\title{
Entrevista ao arquiteto Giorgio Santagostino
}

\author{
João Caria Lopes \\ joaocarialopes@gmail.com \\ Atelier BASE | Centro de Estudos de Arquitetura, Cidade e Território da Universidade \\ Autónoma de Lisboa (CEACT/UAL), Portugal
}

Ricardo Carvalho

rcarvalho@autonoma.pt

Centro de Estudos de Arquitetura, Cidade e Território da Universidade Autónoma de Lisboa (CEACT/UAL), Portugal

Para citação: LOPES, João Caria; CARVALHO, Ricardo - Entrevista ao arquiteto Giorgio Santagostino. Estudo Prévio 16. Lisboa: CEACT/UAL - Centro de Estudos de Arquitetura, Cidade e Território da Universidade Autónoma de Lisboa, 2019. ISSN: 2182-4339 [Disponível em: www.estudoprevio.net]. DOI: https://doi.org/10.26619/2182-4339/16.2

Creative Commons, licença CC BY-4.0: https://creativecommons.org/licenses/by/4.0/

\section{É com enorme prazer que hoje temos como nosso convidado o arquiteto e professor Giorgio Santagostino. Seja bem-vindo. Queríamos começar por pedir que nos contasse um pouco do seu percurso académico, dos professores e exercícios marcantes.}

Antes de tudo, obrigado por este convite, obrigado pela possibilidade de estar cá convosco, fico sempre satisfeito por ter a possibilidade de falar sobre o próprio trabalho. Fiz o curso no Politécnico de Milão, que, na altura, era uma escola com quase catorze mil inscritos, não havia frequência obrigatória, era um estilo que vinha já dos anos setenta, de uma escola bastante politizada. Na altura, é claro, era muito marcada pela escola de Aldo Rossi e de Giorgio Grassi, que era o arquiteto presente como professor. Eu assisti a algumas lições do Grassi, mas tentei sempre encontrar uma linha paralela, não sei porquê, um pouco porque não tinha muito tempo para ficar parado. Ou seja, na altura, não era suposto acabar o curso em cinco ou seis anos, era suposto ficar lá mais tempo, era o professor que decidia quando era possível acabar. Mas, Milão é a minha cidade, portanto, na altura, não senti uma grande diferença na passagem do liceu á universidade.

A grande experiência forte foi o ano em que estudei cá em Portugal, de facto. Foi no meu quinto ano (em Itália para além do quinto ano, há uma tese de dois anos e tal, que fiz depois), na altura, este programa Erasmus foi muito marcante para mim, em 
todos os sentidos. Cheguei aqui, a uma escola muito mais pequena, ainda no centro, na Baixa, em Belas Artes, e adorei logo isso. Tive a sorte de fazer o projeto de quinto ano com João Luís Carrilho da Graça e isso foi, como podem imaginar, muito marcante, porque chegando de uma cultura muito historicizada, encontrei aqui uma aproximação ao projeto muito mais direta, muito mais pragmática. Descobrir o uso da maquete como metodologia projetual, e não como resultado final, como era corrente em Milão, foi incrível. E paralelamente, o facto de sair de casa, o facto de viver sozinho e toda a experiência que a isso está ligada foi também importante.

Outra parte fantástica de estar em Portugal era, por assim dizer, "assaltar" obras, ou seja, era normal, com um grupo de estudantes, no fim de semana, entrar nas obras às escondidas (o controle na altura, não era como hoje). Portanto, esta aproximação à obra, entrar nas obras de Álvaro Siza, nas obras de João Luís Carrilho da Graça, foi uma coisa marcante. É claro que isso não foi só no Erasmus, porque depois voltei, para o estágio, etc. Portanto foi ao longo dos anos que visitei a escola de Setúbal em construção, de Álvaro Siza, a Biblioteca de Aveiro em construção (andei lá no telhado), ou seja, há experiências que marcaram mesmo. E' evidente que depois disso não se pode voltar atrás. Voltas para Itália com uma maneira diferente de ver as coisas.

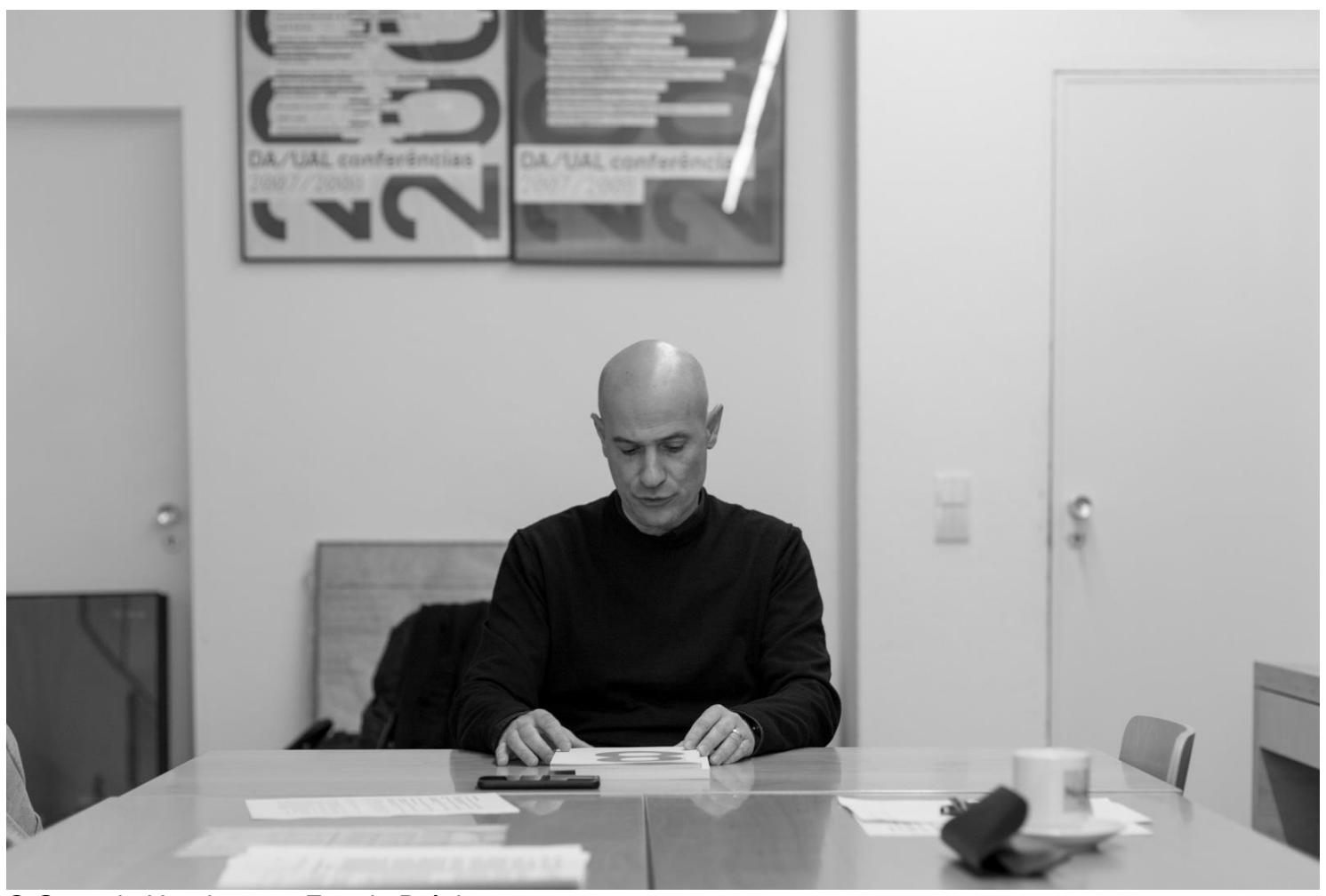

(C) Gonçalo Henriques + Estudo Prévio

$\mathrm{Na}$ altura, Portugal estava num momento de grande expansão, a entrada na comunidade europeia, etc., grandes obras, grandes arquitetos, era um momento, digo eu, muito prospero. Quando voltei para Milão licenciei-me com o arquiteto professor Fredi Drugman, que era um professor da "velha guarda", mas muito aberto (ele 
estudou com o Franco Albini, e foi assistente dele também), fora daquele contexto um pouco "Rossiano", digamos, e consegui acabar o curso com um projeto que tinha a ver muito também com a experiência de cá.

E depois, a experiência não acaba, porque nunca se para de estudar, por isso, voltei a Portugal em vários momentos, e passei por vários ateliers. A formação real faz-se nestes ateliers, porque, afinal, a escola nunca te dá uma formação muito técnica e não se sai da escola muito preparado, eu acho. Iniciei no atelier do Fernando Salvador e Margarida Grácio Nunes (onde encontrei o Ricardo Carvalho), concluindo com uma experiência mais longa no atelier de João Luís Carrilho da Graça, tendo sido, finalmente, a maneira de entrar mais em contacto com o trabalho dele. E foi ali que eu e a Mónica Margarido nos conhecemos. Foi a experiência final da formação (já tinha trinta e tal anos), porque, de facto, teve um impacto muito forte entrar num atelier muito estruturado, com um sistema muito bem planificado de desenhos, de maneiras de organizar e de gerir um projeto de execução. Se bem me lembro, os primeiros projetos de execução que fiz foram ali. Penso que a nossa base nasce mesmo desta experiência muito intensa (na altura trabalhava também aos fins de semana, ou à noite) era um período de grande impacto.

Deixa-me voltar um pouco atrás. Quando nós nos conhecemos, no final dos anos noventa e trabalhámos juntos (o que foi ótimo, tínhamos uma sala só para nós) eu lembro-me de que tu tinhas uma particularidade como arquiteto - é que tu já tinhas construído.

Sim, é verdade.

\section{Construíste muito jovem, queres contar-nos essa experiência?}

Sim, eu, como estava a dizer, também na universidade não gostava de estar parado, o único meio que conhecia na altura era participar em concursos. Fiz com outros colegas pequenos concursos em Itália, e se não foi o primeiro, o segundo ganhámos (já é uma coisa muito antiga): eram habitações sociais, uma remodelação com ampliação de um antigo edifício escolar, com oito ou nove pequenos apartamentos num contexto agrícola, fora da cidade de Brescia. E foi uma situação, não posso dizer marcante, foi um concurso, era um projeto para fazer, mas depois infelizmente não nos deram a direção da obra, como era costume na altura (e ainda é hoje assim). Portanto, são aquelas coisas que nascem, de certa forma, mas depois são como um filho que tem de ir um pouco sozinho. Penso que a obra foi acabada mais tarde, e foi acabada, devo dizer, mais ou menos como o projeto, mas, lá está, nunca há aquele controlo que seria possível.

Certo, mas fez de ti um arquiteto italiano muito diferente da esmagadora maioria, porque, se confrontarmos a experiência italiana com a portuguesa, há exatamente esta vertigem de ser muito difícil construir, e tu, um arquiteto italiano que se interessou por Portugal, quando vens para Portugal, já depois da universidade, já vens com uma experiência de uma obra, o que também fez de ti um caso muito diferente. 
Sim... Quando ia pedir trabalho em qualquer atelier, mostrava o portefólio, lembro-me, que às vezes diziam "como é que está cá agora a pedir trabalho como colaborador?". Quando estava cá, também costumava trabalhar á noites, e nos fins de semana, continuava esta minha atividade secreta de participação em concursos. Até ganhei mais um, que foi construído a seguir, quando voltei. Mas é claro que são experiências, devo dizer, que feitas assim, sem uma estrutura bem organizada, sem na altura ter a noção da importância disso, que não aproveitei muito. Também porque voltei para Portugal, deixando um pouco este arranque, não estou arrependido disso, mas não posso dizer que teve uma continuidade. São obras que já são muito antigas, têm o reflexo também de Portugal, como é evidente, mas que, depois, como tudo aquilo que é obra pública em Itália, não conseguimos gerir e controlar até ao fim.

Mas, claro, tudo é experiência e são obras, ainda hoje posso mostrar o projeto dessas casas populares, e com toda a modéstia, não são nada más. Mas sempre tive a ideia de olhar para a frente, não tinha ideia de parar nestas províncias italianas, não sei se fiquei apaixonado por Portugal, para depois deixar tudo outra vez, mas isso foi a minha sorte, porque depois, tive a oportunidade de cruzar-me com pessoas especiais.

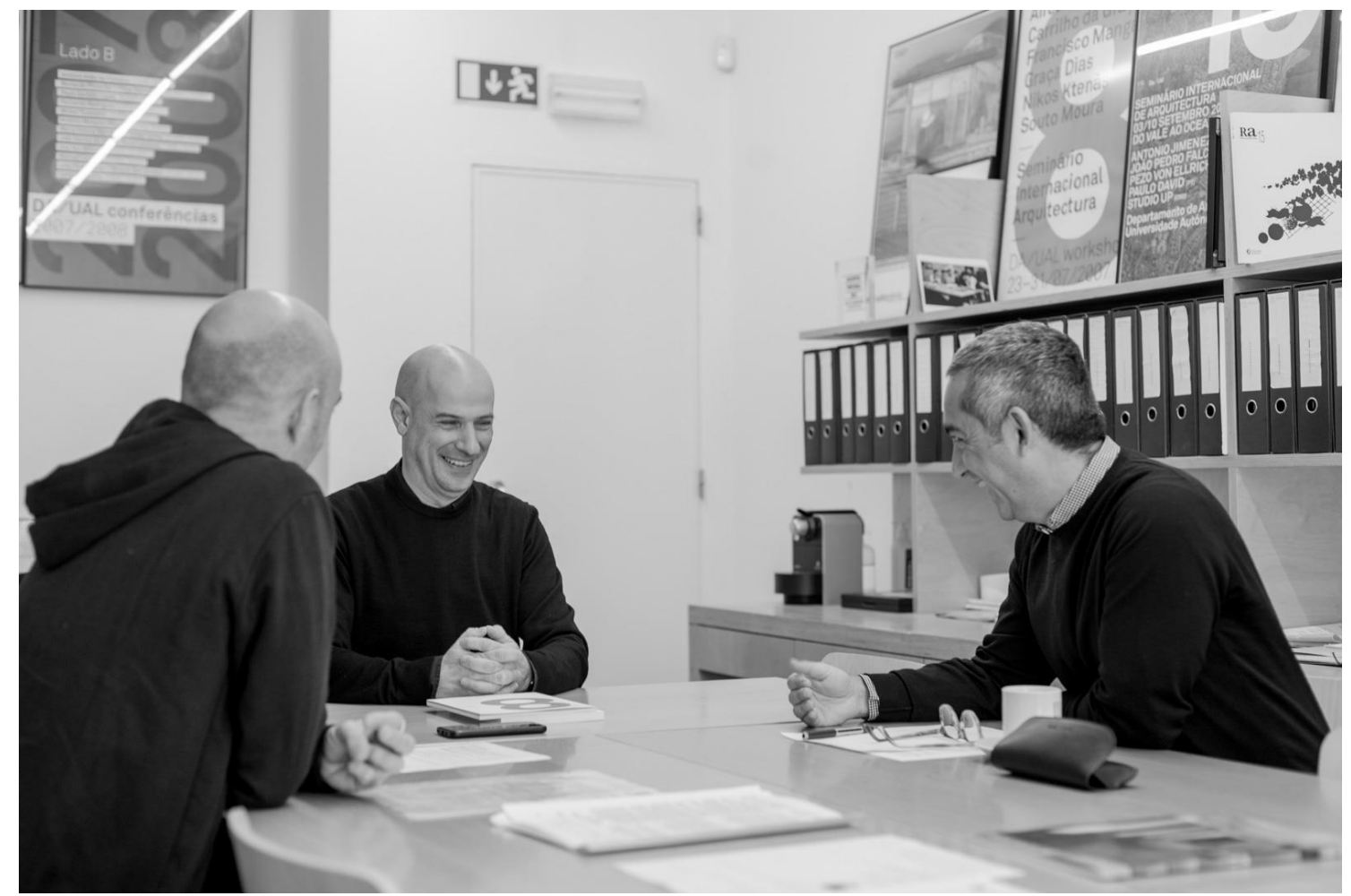

(C) Gonçalo Henriques + Estudo Prévio 


\section{E o que é que motivou, com a Mónica Margarido, a decisão de não fazer o atelier cá e fazer em Itália?}

Essa é uma pergunta por um lado difícil e por outro lado fácil. Como sabem, na altura, se posso falar pela Mónica, sair de Portugal era uma coisa especial, ou seja, é lá o centro da Europa. Portanto, a Mónica como qualquer arquiteto(a) português(a) viu a Itália, Milão em particular, um pouco como um centro - está ali, perto de tudo. Para ela foi uma coisa importante: sair, abrir canais. Para mim era um pouco voltar à ideia de ter ali alguns contactos mais diretos e pensar que podia ser um sítio onde poderia trazer a experiência de cá para lá e ser especial lá, portanto ter uma mais valia, esta foi um bocado a ideia. $E$ posso dizer que em parte aconteceu, em parte não aconteceu. Ou seja, depois não está tudo lá à espera de ti, portanto, é duro, como qualquer mudança, e foi bastante duro para a Mónica. Obviamente no inicio Milão não é fácil como cidade. É uma cidade um pouco cinzenta, de trabalho. Mas, foi uma decisão planificada.

\section{E baseada em concursos, ou seja, não foram com uma encomenda?}

Não, fomos para lá mesmo de maneira muito aventureira. Abri o meu pequeno espaço de trabalho, que era um coworking, como agora se usa, um grande espaço com muitos arquitetos. Saí daqui com um portátil e uma impressora, o que, para mim, era já ter muito, e comecei concursos. A Mónica, para aprender um pouco a cultura e a língua, etc., decidiu fazer uma experiência, que durou quase dois anos, num atelier de Milão.

\section{Com quem?}

Com Rodolfo Dordoni, Dordoni arquitetos, que é bastante famoso no âmbito do design, mas que, na altura, abriu uma secção de arquitetura, onde havia um bom ambiente, porque havia muitos ex-colaboradores de Cino Zucchi que tinham aberto esta nova secção. E ela lá cruzou-se também com pessoas que tinham trabalhado já com o João Luís, nomeadamente o nosso amigo Federico Tranfa, tendo, portanto, encontrado lá um pedaço de Portugal à sua espera. Bom, depois desta experiência, juntámo-nos e seguimos o nosso plano, o que cá era completamente estranho, porque cada vez que na altura nós contávamos que fazíamos só concursos, ninguém acreditava: "como é que vocês conseguem sobreviver?"

\section{Essa cultura de fazer concursos no atelier continua ainda hoje.}

Sim, é um atelier quase conhecido um pouco por esta atividade um bocado até estranha, devo dizer. Não somos os únicos que fazem isso, é verdade, mas quando começas a fazer concursos, entras num túnel e é difícil sair desse túnel, por vários motivos. Não crias uma ligação com um cliente, ou seja, não há clientes que te pedem uma casa sabendo que tu fazes escolas e ginásios, toda a gente pensa que tu estás mais virado para aquele tipo de trabalho e, depois, é difícil de sair. Tem de ser sempre por concurso, porque não há uma continuação na obra pública, não é por lei permitido, portanto, acabas um e tens de inventar qualquer coisa. Mas há uma parte muito 
bonita, que é aquela parte de nunca estar sem trabalho, nunca estar sem motivações, nunca estar sem um momento mágico. Há um momento especial em que tu encontras uma solução, e aquele é um momento de criação muito bom, que enriquece a vida. Eu e a Mónica zangamo-nos um com o outro, como é normal, no atelier há discussões sobre o que fazer, mas penso que isto cria uma base de felicidade porque a arquitetura, depois, é grande parte da nossa vida, com certeza.

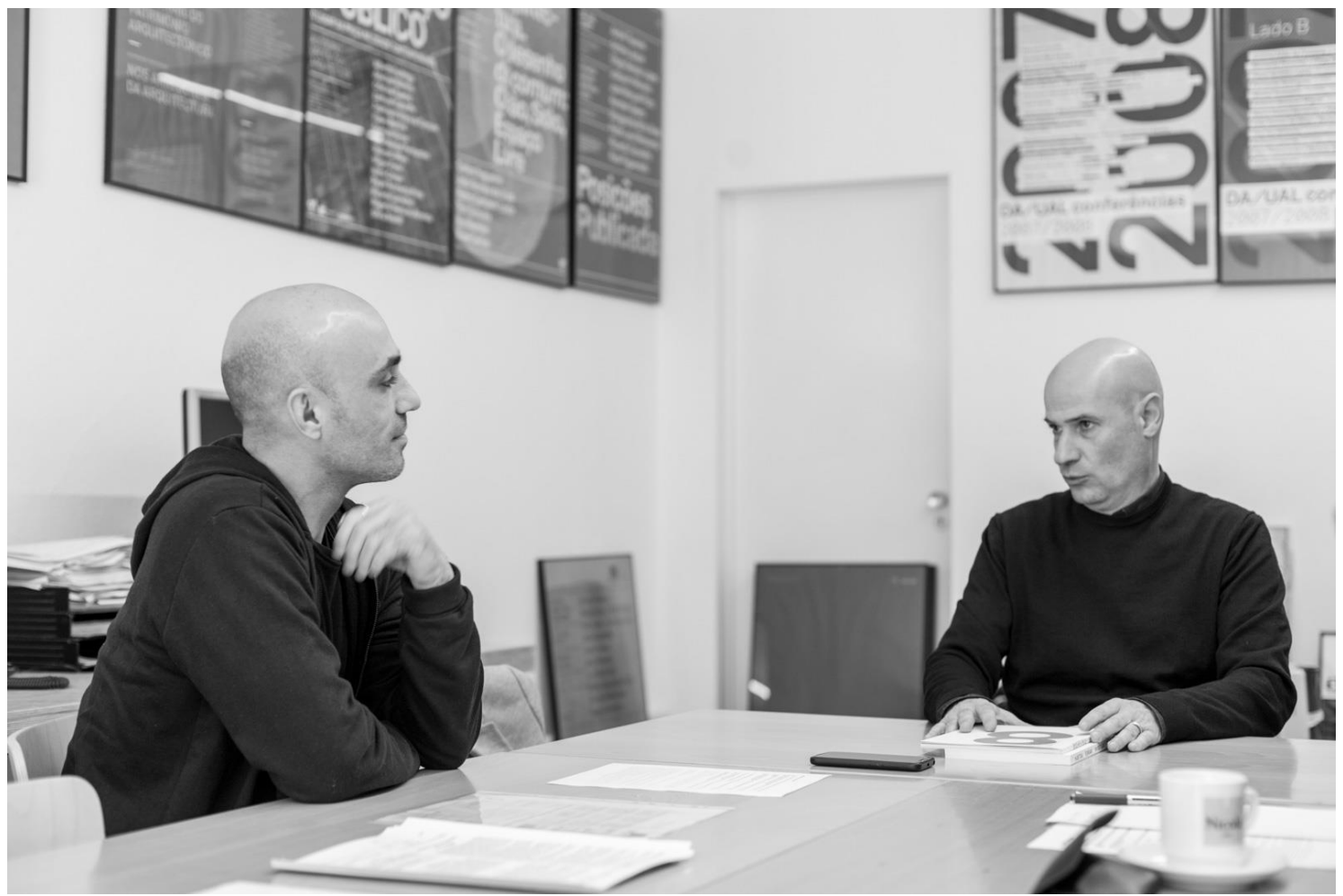

(C) Gonçalo Henriques + Estudo Prévio

E, há pouco, estavas a dizer que depois de fazeres o teu atelier e começares a ter trabalho e concursos e ganhares concursos, foste convidado para ir para Mendrisio. Conta-nos um pouco dessa experiência.

Sim, foi quase logo no início em que eu e a Mónica termos ido para Milão, o Francisco e o Manuel Aires Mateus foram convidados pela Academia de arquitetura de Mendrisio, na Suíça, para dar aulas. Eu tinha uma relação de amizade com eles, tínhamo-nos cruzado aqui, mas nunca tinha trabalhado com eles. E estas coisas nascem assim um bocado casuais, fui convidado para fazer criticas aos alunos finalistas, e fiquei muito emocionado, como podem imaginar. $\mathrm{Na}$ altura, não é que fosse muito jovem, mas era uma coisa bastante especial para mim, até porque o outro arquiteto convidado, era o Gonçalo Byrne. Foi muito forte, e depois convidaram-me mais duas ou três vezes para fazer outras criticas finais e pensei: "bom, não correu mal!". E, depois, convidaram-me para ser assistente deles, e isso foi outra grande parte da formação, que marcou e marca ainda. Eu conheço muito bem o trabalho deles, mas agora acho ainda mais que são dois arquitetos incríveis e duas pessoas 
especiais. E o facto de estar lá não é só pela arquitetura, mas também pela relação com eles. $\mathrm{E}$ as condições desta universidade (estou lá há catorze anos, praticamente), são fantásticas. Nós temos aulas por turma, os alunos podem deixar lá tudo na própria mesa, têm espaço para deixar lá as maquetas, é uma universidade onde se pode realmente praticar como se fosse um grande atelier. Há revisões semanais, tudo é feito por maquete, é um espaço em que tudo é ligado e isso é sempre quase como uma extensão e pesquisa do trabalho deles... É uma experiência um bocado difícil de contar agora em duas palavras, são muitos anos.

Mas, por exemplo, eu acho que posso dizer que conheço bem essa experiencia até porque já estivemos junto várias vezes em Mendrisio e eu creio que há uma diferença substancial entre o trabalho que tu fazes na universidade com os Aires Mateus e o teu próprio trabalho que é: o Manuel e o Francisco Aires Mateus relativizam completamente o programa, o programa não é um dado para a equação na investigação e vocês, no atelier, potenciam muito a ideia de programa, certo?

Sim, é certo.

\section{Como é que lidas com esta questão?}

É assim, eu sempre tentei não ser a cópia de qualquer coisa. Hoje em dia, é muito difícil não ser uma cópia de tudo, a arquitetura ficou muito difícil para se gerir a si mesma. Sim é verdade, voltando aos concursos, há sempre um pedido e uma resposta a dar e há um programa. Recentemente, nós estamos a investir muito nos concursos da Suíça, porque são muitos, porque são bons, são bem organizados e fazemos isso com o atelier de apoio lá, Krausbeck architetti. Nós estamos sempre à procura de dar uma resposta que seja pragmática, simples e que haja uma relação com aquilo que são as expectativas da vida, de uma escola, de um espaço. Mas eu acho que tem a ver também com o trabalho com João Luís ou com o Francisco e o Manuel, ou seja, há sempre uma grande dedicação a àquilo que são os pedidos e a quais devem ser as respostas a estes pedidos. Depois há formas diferentes para fazer isso e tentamos sempre ter a capacidade, digo eu, de responder a tudo - não só a uma coisa que nós queremos - mas responder a tudo, há um programa que temos de respeitar. Numa organização muito clara e, se a resposta não é dentro daquilo que pediram, já estás fora; ou seja, não há brincadeiras e isso, para nós, é uma base muito importante para não perder tempo. Em Itália, é tudo um bocado mais confuso, num concurso pode ser que o que ganha seja aquele que tem uma ideia um bocado estranha, sai daquilo, não responde, custa mais, mas ninguém controla. Não, na Suíça isso é muito certo.

\section{Há um pragmatismo?}

Sim.

\section{E revês-te nesse pragmatismo?}


Sim. Por um lado, trava um bocado a nossa originalidade, mas, por outro lado, sinto que é leal, é um trabalho mais leal. Para dizer a verdade, eu não respondi à tua pergunta porque a pergunta era mais ou menos outra - eu gosto muito do trabalho do Francisco e do Manuel, portanto sou influenciado, mas tento sempre não ser demasiado um "aluno" deles, não porque não quero, mas porque não acho sério em relação a eles. Acho o trabalho deles incrível.

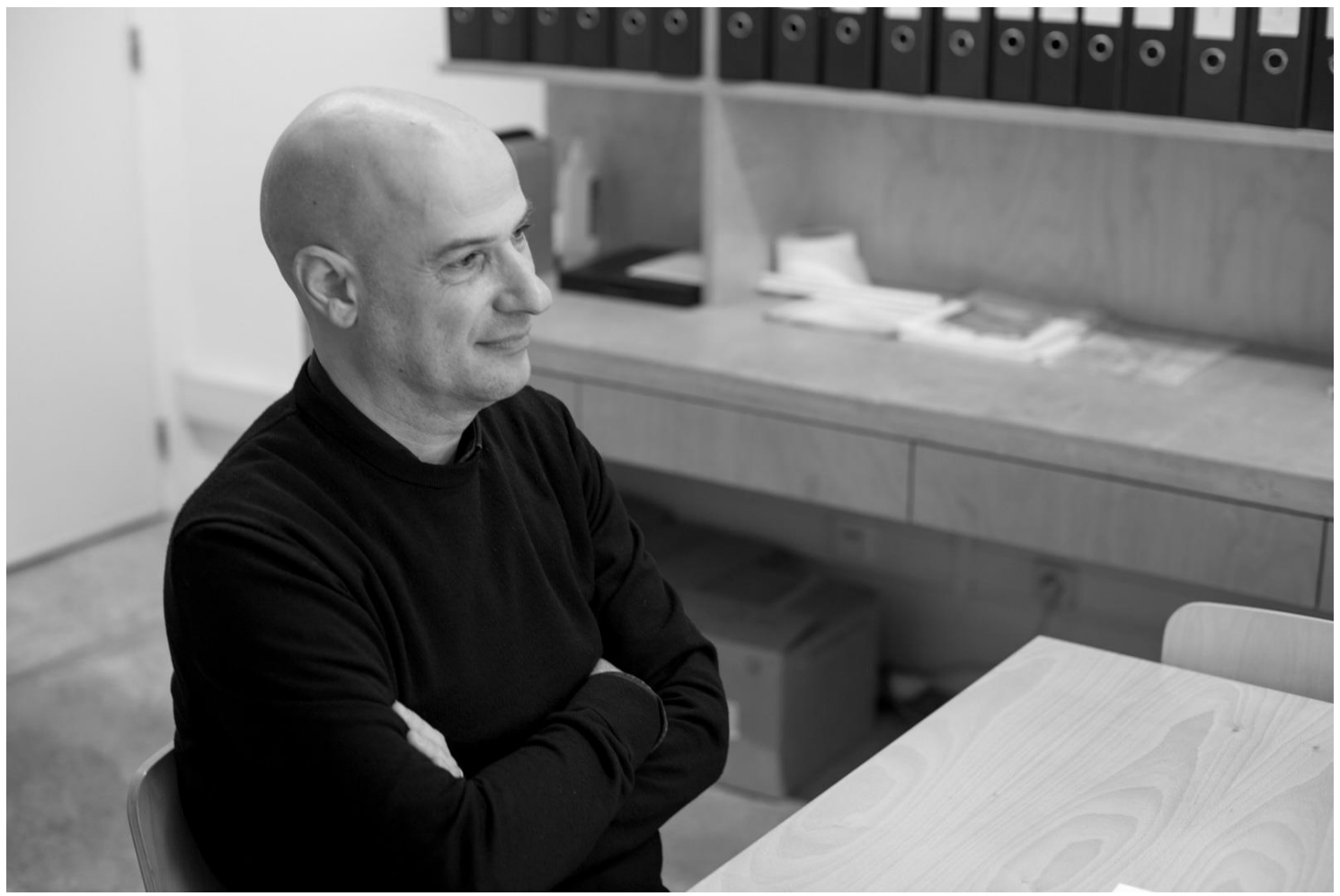

(C) Gonçalo Henriques + Estudo Prévio

No teu trabalho, também falas sobre a reversibilidade do espaço, e da possibilidade de o espaço poder voltar a ser o que era. Isso também é um dado adquirido no teu atelier?

Sim, nas obras públicas é normal que o espaço possa mudar de função, isso aconteceu sempre na história. Nós temos conventos que agora são museus, ou escolas, antigos hospitais que foram transformados. Esta reversibilidade é uma base da nossa atividade, mas eu acho que esta possibilidade, para quem está a gerir ou promover, oferece uma boa base para poder, no futuro, alterar as condições. $\mathrm{Na}$ arquitetura, quando há uma estrutura, e quanto mais clara for essa estrutura, melhor podemos conseguir introduzir um programa num sistema. Esta forma de criar uma estrutura muito clara, para nós, ajuda a formalizar o projeto. Ajuda-nos a não ter divagações, para a obra poder ser construída de uma maneira também fácil, económica, para funcionar bem. E o minimalismo construtivo tem um fascínio: se a estrutura é bonita, tem uma força em si. Isso, claro, nem sempre é possível, mas dá- 
nos a sensação de que é a estrada certa a seguir. A coisa engraçada é que na Suíça tu podes fazer isso com o betão, ou seja, não existe a ideia que a reversibilidade só é possível com a madeira, ou com o aço, etc. O betão é visto como um material que pode ser reversível, é um material que pode perfeitamente ser usado numa futura remodelação.

\section{Mas, para quem começou a conversa a recusar o legado Rossi e Grassi, estamos exatamente a discutir esse legado.}

Claro (risos). Existe um pouco de "escola" que fica marcada, eu tenho vários livros do Giorgio Grassi e foi no inicio una grande referência. A minha tese final no Politécnico era uma biblioteca, toda em tijolo á vista, e reflete muito a atmosfera dos projetos dele, com certeza.

Gostava de perguntar: num texto que eu li sobre o teu trabalho, falava muito sobre a relação entre levar a investigação para dentro do atelier e fazer com que, mesmo os pequenos projetos de remodelações, sejam um motivo para fazer investigação sobre o habitar. Hoje em dia, pelo menos em Portugal, fala-se muito sobre as novas metodologias de investigação em arquitetura, que têm a ver sempre com relacionar o trabalho que se faz dentro do atelier com a academia. Como te posicionas sobre isso?

Então, como fizemos algumas remodelações, sobretudo a amigos, é claro que a escala mais doméstica é aquela escala onde o arquiteto pode investigar muita coisa. Posso dizer que nunca tivemos a grande oportunidade de ter um trabalho onde se pudesse chegar a um ponto máximo, digamos. Voltando outra vez um bocado a estes trabalhos de obra pública, é evidente que há sempre uma contínua investigação. Quando num ano fazes quase dez concursos, é evidente que em cada projeto há uma tecnologia a propor, há um sistema de construção, que muda muitas vezes radicalmente de um projeto para o outro. Esta é uma investigação, sobretudo na relação que temos com as especialidades e com outros parceiros arquitetos, que nos oferece uma maneira de crescer; é mais uma investigação que surge no relacionamento com outras pessoas, novos impulsos para atuar, novos materiais, novas tecnologias que surgem, às vezes, por acaso, não é uma coisa de que estamos à procura.

O nosso atelier nunca parou muito tempo para pensar no que estamos a fazer. Sempre se focou na atividade - digo isso esperando que seja a maneira mais forte - de fazer arquitetura. Ou seja, é uma parte fundamental da nossa vida, mas também nunca demos grande espaço para fixar, organizar coisas... Não sei se estou a responder bem à tua pergunta, porque nós achamos que não construímos uma linha nossa, mas depois, quem olha de fora diz "que não, o vosso trabalho tem uma continuidade, tem uma relação". Mas eu penso que em cada projeto há um contexto, há uma resposta, há condicionantes. $E$ acho que as condicionantes são aquelas que organizam a pesquisa. Temos condicionantes e a nossa pesquisa é responder às mesmas da maneira mais direta, eu acho. 


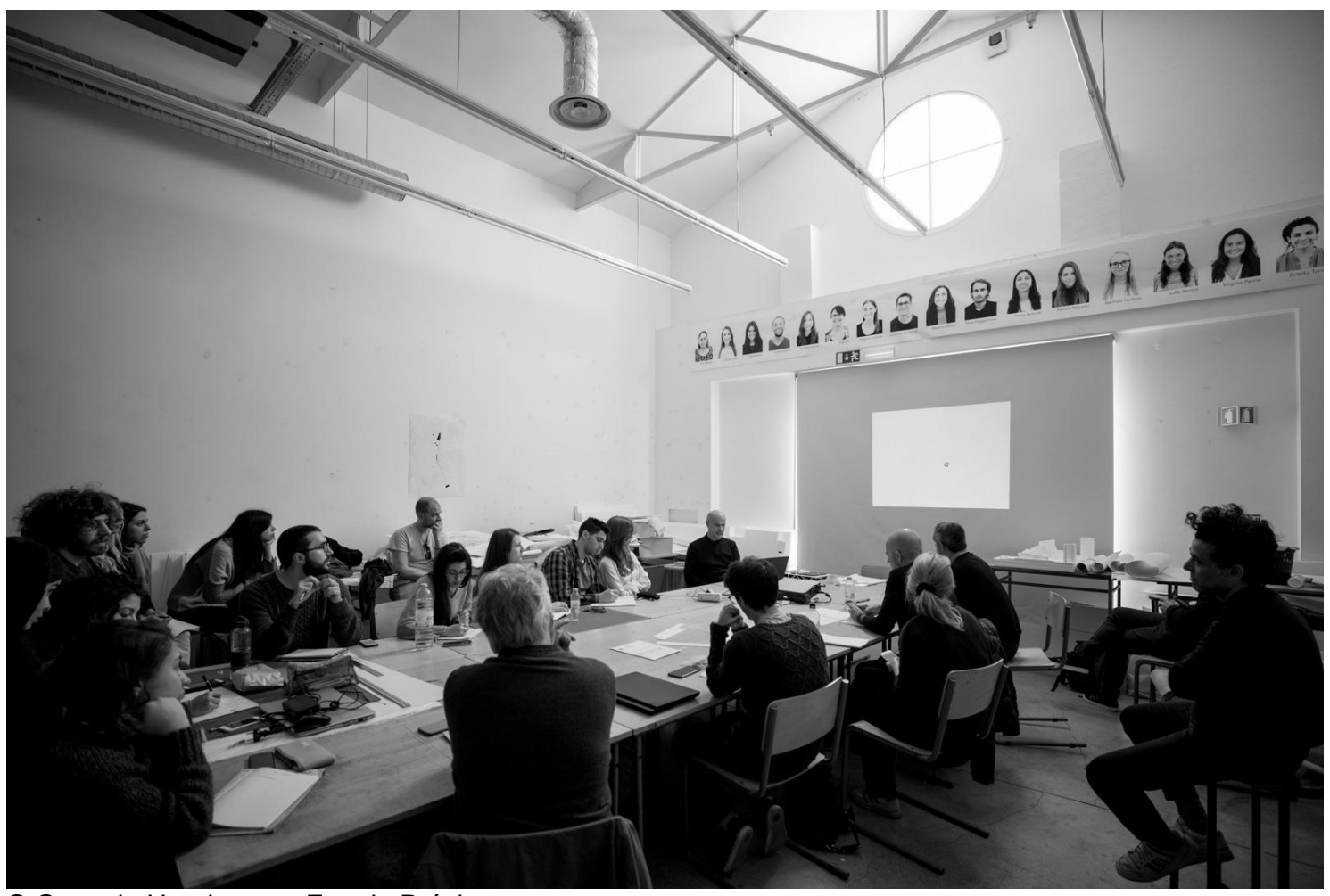

(c) Gonçalo Henriques + Estudo Prévio

Tu tens uma possibilidade interessante para nós, em Portugal, tu consegues estar dentro do que é que se faz em Portugal, mas ao mesmo tempo estar fora. Para nós é interessante saber um pouco como é que vês a arquitetura portuguesa, qual é a tua opinião sobre o que é que hoje em dia se faz cá?

Eu não estou a par de tudo. Eu penso que está a mudar tudo muito rapidamente. A situação italiana, onde nós vivemos (para a qual era preciso agora uma entrevista de algumas horas), é uma situação em que as obras públicas, como podem ler nos jornais, estão todas paradas, há uma grande confusão política... Mas também já há anos que é tudo organizado à volta da economia, de requisitos económicos. E a lei das obras públicas é uma lei igual para todos - para quem constrói uma autoestrada e para quem constrói um pequeno ginásio. Nós estamos há quase um ano à espera que arranque um trabalho publico italiano, continuam a pedir coisas, ainda não pagaram... Nós olhamos para Portugal como um país (pela minha experiência passada e recente) que, mais ou menos, sempre entregou os projetos a bons arquitetos. Se calhar, nem sempre através de concurso, às vezes com empreitadas diretas, mas conseguiu sempre, pelo menos, saber quais são os arquitetos de qualidade; e esses arquitetos tiveram oportunidade de construir aquilo que é a escola do Porto, mas também a escola de Lisboa. Agora aqui em Lisboa há muito investimento - chamam jovens arquitetos, da minha idade (já não muito jovens...) da nova geração, que estão a fazer obras de intervenção na cidade, e eu acho isso fantástico. A situação italiana é o contrário disso, portanto, é difícil não dizer que a situação em Portugal é, para nós, um 
paraíso. E a Suíça é outro nosso lugar que olhamos com interesse, porque ali o arquiteto é ainda o centro em tudo o que está ligado ao projeto. Aqui também existe uma luta, na Ordem dos Arquitetos (porque também aqui existem coisas que estão a começar a correr mal), mas os arquitetos conseguiram enfrentar a política, o que em Itália não aconteceu. A Itália já começou essa degradação há trinta ou quarenta anos, mas agora, se posso dizer, a arquitetura, o arquiteto como pessoa, em Itália, não existe.

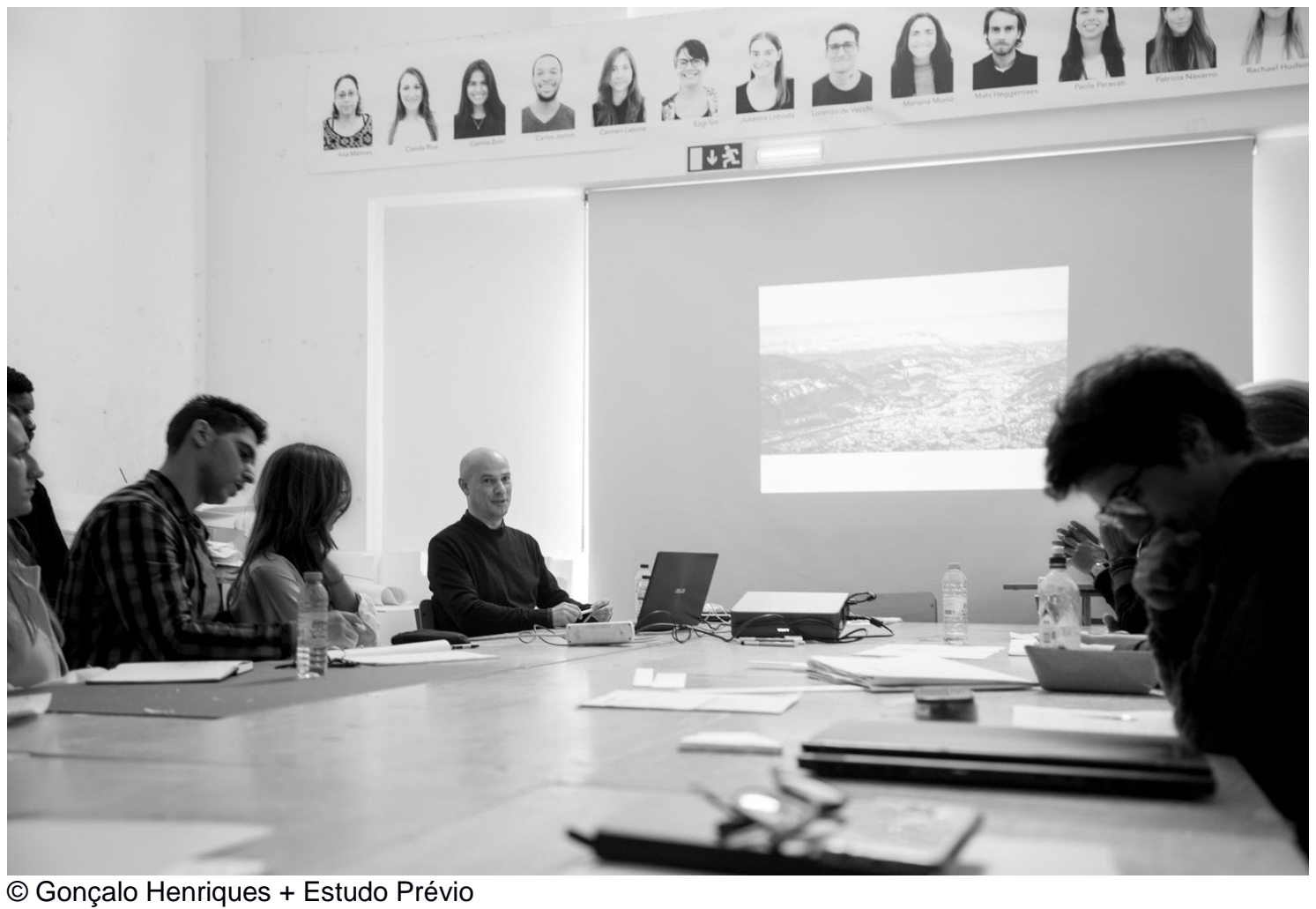

Mas eu acho que a pergunta anterior tinha também a ver não só com essa perspetiva profissional, que é importantíssima, mas tinha também a ver com uma perspetiva cultural, ou seja, se ainda existe uma perceção de uma arquitetura portuguesa, não é?

Eu acho realmente que sim, diretamente, ou seja, temos o arquiteto Álvaro Siza que está ainda a construir como se fosse um jovem. Agora está a construir fora de Portugal, mas é marcadamente português. E depois temos os Aires Mateus, de facto, que atingiram um reconhecimento a nível internacional e são uma referência. $E$ temos também o arquiteto João Luís Carrilho da Graça, que recentemente acabou o Terminal de Cruzeiros; portanto, perfeitamente dentro de uma imagem cultural forte. É verdade que a atenção dos anos noventa era a Espanha e Portugal, agora a atenção é mais a Suíça, Japão, América do Sul, claro, são coisas novas nos jornais que mais investigam sobre o momento. 


\section{Norte da Europa também.}

Norte da Europa, claro. A Bélgica agora está totalmente na moda, com os ateliers superconceituados, etc. Portugal é ainda visto como uma estrutura muito sólida e reconhecida. No entanto, apercebi-me que começou a entrar um bocado de Europa aqui, como em Itália - toda esta burocracia eletrónica, de selos, entregas nos serviços públicos. Tive problemas com entregas digitais, que em Itália já temos há algum tempo, e espero que isso não vá impedir a expressividade de alguns aspetos da arquitetura portuguesa, porque de facto é importante não apagar esta liberdade que aqui se sente.

\section{Vês os próximos anos do teu atelier, ou da produção internacional em arquitetura de uma maneira positiva?}

Sim, o ano passado ganhamos dois concursos importantes e temos uma perspetiva diferente, o tamanho do atelier é igual, mas ficámos mais descansados. Agora, nunca é possível parar, sinto que temos uma base mais tranquila, mais forte para avançar noutras coisas, mas, sinceramente, já tive períodos fantásticos e outros muito difíceis. Portanto, é continuar. Nunca parei de pensar da mesma forma, temos de ter cuidado, não sou daqueles que ganham um concurso e duplicam o atelier, somos ainda eu, a Mónica e um colaborador. E nós também não queremos abdicar de uma parte da vida - a arquitetura é o centro, como podem imaginar, mas também costumamos parar por períodos longos. $O$ atelier às vezes fecha vários meses no verão. Nunca tivemos a ambição de uma estrutura grande, não queremos que a estrutura fique muito maior do que aquilo que é. O nosso objetivo não é crescer de maneira que fique fora do nosso controlo, também penso que isso nunca vai acontecer, digo eu... Claro que queremos ter mais trabalho, obviamente, mas queremos ser cuidadosos. 